\title{
MSH2 and CXCR4 involvement in malignant VIPoma
}

Sven Müller ${ }^{1,4}$, Susan Kupka ${ }^{1,4}$, Ingmar Königsrainer ${ }^{1,4}$, Hinnak Northoff ${ }^{2,4}$, Karl Sotlar $^{3,4}$, Thomas Bock ${ }^{3,4}$, Reinhard Kandolf ${ }^{3,4}$, Frank Traub ${ }^{1,4}$, Alfred Königsrainer ${ }^{1,4}$ and Derek Zieker ${ }^{1,2,4,5^{*}}$

\begin{abstract}
Background: Vasoactive intestinal polypeptide secreting tumors(VIPomas) are rare endocrine tumors of the pancreas with an estimated incidence of 0.1 per million per year. The molecular mechanisms that mediate development of VIPomas are poorly investigated and require definition.
\end{abstract}

Methods: A genome- and gene expression analysis of specimens of a primary pancreatic VIPoma with hepatic metastases was performed. The primary tumor, the metastases, the corresponding healthy tissue of the liver, and the pancreas were compared with each other using oligonucleotide microarrays and loss of heterozygosity $(\mathrm{LOH})$.

Results: The results revealed multiple $\mathrm{LOH}$ events and several differentially expressed genes. Our finding of $\mathrm{LOH}$ and downregulation was conspicuous in the microarray analysis for the mismatch repair gene MSH2 in the primary pancreatic VIPoma tumor, the hepatic metastasis but not in the corresponding healthy tissue. Further a strong overexpression of the chemokine CXCR4 was detected in the hepatic metastases compared to its pancreatic primary. With a review of the literature we describe the molecular insights of metastatic development in VIPoma.

Conclusion: In VIPoma, defects in the mismatch repair system especially in MSH2 may contribute to carcinogenesis, and increased CXCR4 may be associated with liver metastasis.

Keywords: VIPoma, MSH2, CXCR4, Microarrays, LOH

\section{Background}

Vasoactive intestinal polypeptide secreting tumor (VIPoma) is a rare tumor associated with watery diarrhea, hypokalemia, and achlorhydria (WDHA) [1]. The estimated incidence is approximately 0.1 per million per year [2]. VIPomas are mostly located in the pancreas, although they have been already detected in the bronchial system, colon, liver, adrenal gland, and sympathetic ganglia [3,4]. The major causes of death concerning VIPomas are dehydration and renal failure [5]. Clinical symptoms lead to the diagnosis. When symptoms present several patients already have metastasis. The only curative approach is surgical resection [6]. Until now the molecular mechanisms that mediate

\footnotetext{
* Correspondence: derek.zieker@med.uni-tuebingen.de

'Department of General, Visceral and Transplant Surgery, Tübingen, Germany

${ }^{2}$ Department of Transfusion Medicine, Tübingen, Germany

Full list of author information is available at the end of the article
}

development of metastases of VIPomas require definition and were not investigated yet. Thus, we present this rare entity by investigating a genome- and gene expression analysis of specimens of a primary pancreatic VIPoma with hepatic metastases.

\section{Methods}

Case presentation

A 69-year-old man was referred from an outside hospital to our department with masses in the liver and therapyresistent watery diarrhea. Since 1996 he had suffered from protracted watery diarrhea. At that time the patient received oral rehydration solutions and electrolyte supplementation without regression of the symptoms. In September 1999 ultrasonography was performed and several hepatic masses were detected. Subsequent biopsy of the hepatic masses revealed the diagnosis of metastases due to a malignant VIPoma without evidence of the location of the primary. For further conservative treatment the patient

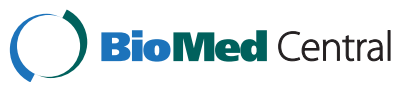


received Sandostatin without regression of the diarrhea. Thus, the patient was administered Rituximab and Roferon additionally, so the progress of the symptoms was impeded. During the course of treatment, minor relapses were compensated using Capecitabine and Cetuximab as additional medication. Regarding side effects of therapy,the patient developed enormous acne. In December 2005 the patient stopped responding to the performed conservative treatment and suffered from massive watery diarrhea (5 to $10 \mathrm{~L} /$ day), hypokalemia, achlorhydria, anemia, and severe metabolic acidosis with consecutive acute renal failure and requiring dialysis. Finally the patient was referred from an outside hospital and was admitted to our hospital and department in February 2006. At admission computed tomography (CT) and magnetic resonance imaging (MRI) were performed. In the liver a $4.7 \times 3.3 \mathrm{~cm}$ mass in segment VII, a $6.6 \mathrm{~cm}$ mass in diameter in segment V/VI, and two lesions with $2 \mathrm{~cm}$ and $1.7 \mathrm{~cm}$ in diameter in segment $\mathrm{V}$ were detected. The findings showed an increase in size compared to a previous CT scan performed in July 2005. Since CT and MRI were not able to reveal the location of the primary a PET-CT with MBq 68-Gallium-DOTATOC was conducted. Enhancement of multiple lesions in the right lobe of the liver and a slight enhancement in the caudal pancreas without morphological circumscribable primary tumor were observed (see Figure 1). No infiltration of lymph nodes or other organs was detected. Due to the censorious condition of the patient, at first a tumor-debulking to decrease the amount of VIP causing the symptoms was suggested. Plasma levels of VIP were between 450 and 650 pmol. Accordingly a hemihepatectomy was conducted in March 2006 whereas the surgeon was able to palpate a lesion in the caudal pancreas intraoperatively. Based on the severe condition of the patient, a simultaneous hemihepatectomy and pancreasectomy was not able to be performed at that time without putting patient's life at risk. A liver weighing $912 \mathrm{~g}$ and measuring $18.5 \times 17.7 \times 8.4 \mathrm{~cm}$ was resected. Pathologic examination and immunohistochemistry revealed metastases due to a malignant VIPoma and expression of Chromogranin-A and Synaptophysin. In time the condition of the patient stabilized. The symptoms improved and the plasma VIP decreased (18 pmol). After a reasonable recovery the patient underwent caudal pancreasectomy and splenectomy in January 2007 with successful resection of the primary tumor in sano. A pancreas specimen measuring $9 \times 5 \times 3 \mathrm{~cm}$ was resected. Pathologic examination and immunohistochemistry revealed a pancreatic neuroendocrine tumor confirming a malignant VIPoma with expression of Chromogranin-A and Synaptophysin. The postoperative course was uneventful and the patient did not show any further symptomatic. The follow-up examinations with CT and MRIdid not reveal any recurrence or clinical symptoms, and VIP plasma levels were low (2 pmol).

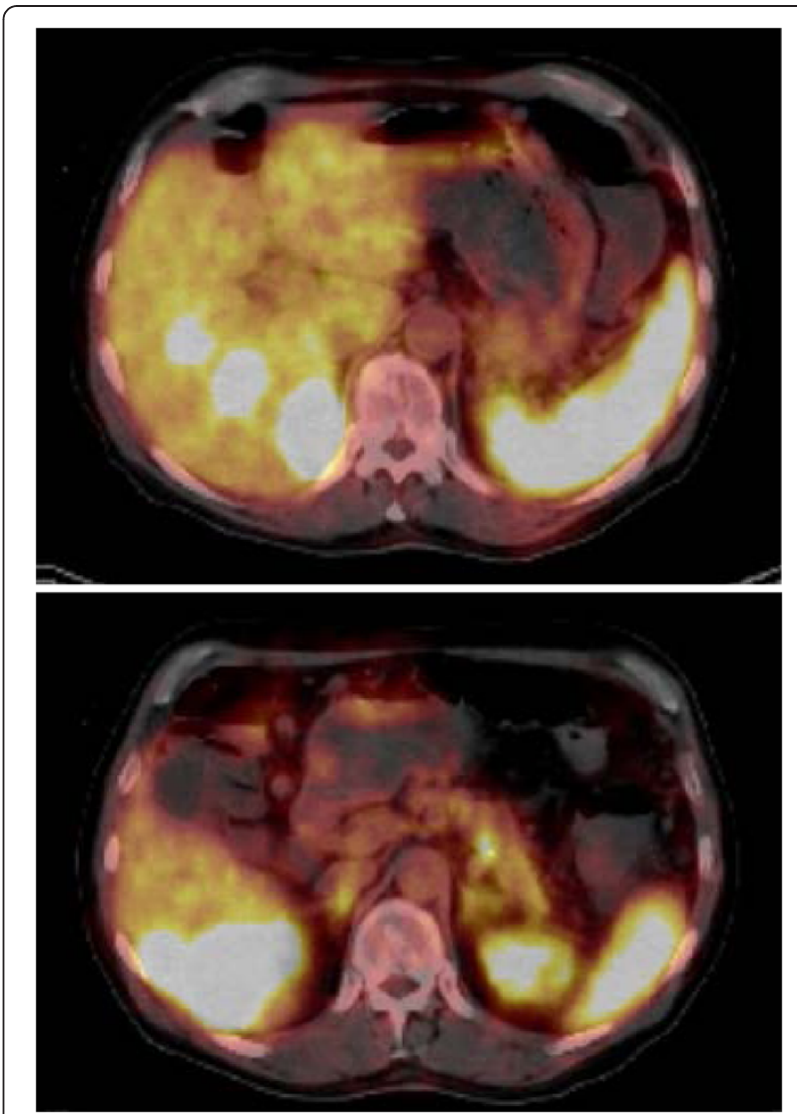

Figure 1 PET-CT with MBq 68-Gallium-DOTATOC showing enhancement of multiple lesions in the right lobe of the liver (upper image) and a slight enhancement in the caudal pancreas (lower image).

\section{Patients and tissue specimens}

Histological proven tissue samples (primary pancreatic VIPoma with hepatic metastases and corresponding healthy tissue of the liver and the pancreas) of this patient were investigated. All tumor specimens were collected by the Department of General, Visceral and Transplant Surgery, University of Tübingen, Germany. Specimens were snap frozen in liquid nitrogen and stored at $-80^{\circ} \mathrm{C}$ until use. Each tumor sample was cryosected, stained with hematoxylin and eosin, classified by two experience pathologists, and re-evaluated by an experienced surgical pathologist. To ensure a tumor content $>80 \%$, microdissection was performed regarding cancer specimens. The patients provided signed informed consent. The study was approved by the local Ethics Committee.

\section{RNA isolation}

RNA was extracted using the NucleoSpin RNA II Kit (Macherey-Nagel, Dueren, Germany). The RNA quality 
and quantity were verified using the Agilent 2100 Bioanalyzer (Agilent Technologies, Palo Alto, CA, USA) and the NanoDrop ND-1000 spectrophotometer (NanoDrop Technologies, Wilmington, DE, USA).

\section{Microarray data generation and statistical analysis}

Material and Methods concerning production and analysis of our oligonucleotide microarrays have been described already by Zieker et al. $[7,8]$. In short:

Microarray analysis was performed using oligonucleotide microarrays $(65 \mathrm{mer})$ produced at the Max Planck Institute, Tübingen, Germany. The arrays contained oligonucleotides for about 900 transcripts, and each oligonucleotide was printed twice. Using 5 oligonucleotide microarrays (including dye-swap) we compared the primary tumor, the metastases, the corresponding healthy tissue of the liver, and the pancreas. Amplification of the sample RNA was performed using Ambion's Amino AllylMessageAmp ${ }^{\mathrm{TM}}$ II aRNA Amplification Kit (Ambion Inc., Austin, TX, USA). Dye-coupling reaction was performed using Amersham CyDye Post-labelling Reactive Dye Pack (GE Healthcare, Buckinghamshire, UK). After an aRNA fragmentation using Ambion's Fragmentation Reagents (Ambion Inc., Austin, TX, USA), hybridization was carried out at $48^{\circ} \mathrm{C}$ for $14 \mathrm{~h}$. The slides were scanned in a microarray scanner (Genetix Limited, Hampshire, UK). The photomultiplier tube voltage was set to $100 \%$ for both red and green channels. The two resulting green and red images were overlaid using ImaGene 5 (BioDiscovery, Inc., El Segundo, CA, USA). Raw data collection was performed using ImaGene v.5.0. Further statistical and bioinformatic analyses were performed using the $\mathrm{R}$ language (www.r-project.org) and the 'limma' (Linear Models for Microarray) package from the Bioconductor project (http://www.bioconductor.org/). As a first step in signal extraction, for each channel we used the mean of the pixel distribution for the foreground signal and the median for the background of each spot as estimators of the raw signal values. All spots were used, regardless of their flag status. The data were normalized using loess normalization on the normexp-background corrected expression values, followed by a dye-swap normalization and in-betweenarray quantile normalization. Both the loess and quantile normalization methods were used as provided in the limma package. On the basis of the $M$ values computed, differentially expressed genes were detected by applying the Welch one-sample $t$-test as implemented in R.

\section{Microsatellite analysis}

DNA was extracted from both tissue and patients' blood using the Gentra-DNA-extraction kit (Biozym) according to the manufacturer's instructions. The following
DNA samples derived from patients' material were used for microsatellite analysis:

M32: primary tumor

M32I: liver metastasis 1

M32II: liver metastasis 2

M32N: normal liver tissue

Data derived from these samples were compared to results derived from blood DNA.

\section{LOH analysis}

Microsatellite analysis was performed applying an extended marker panel for endocrine tumors which was previously established in our department [9]. In brief, markers BAT25, BAT26, D2S123, and D17S250 were amplified in a multiplex PCR (multiplex 1) using the QIAGEN Multiplex PCR Master Mix (Qiagen) under following conditions: final concentration of each forward primer (dye labeled) was $0.2 \mu \mathrm{M}$, of each reverse primer $1 \mu \mathrm{M}$, DNA concentration was $100 \mathrm{ng}$. Asymmetric PCR was used to reduce the ratio between primer signal and amplicon signal thereby improving the fluorescence detection threshold. Thermal cycling conditions were $94^{\circ} \mathrm{C}$ for $5 \mathrm{~min}\left(94^{\circ} \mathrm{C}\right.$ for $30 \mathrm{~s}, 54^{\circ} \mathrm{C}$ for $90 \mathrm{~s}, 72^{\circ} \mathrm{C}$ for $\left.60 \mathrm{~s}\right), 30$ cycles, $60^{\circ} \mathrm{C}$ for $5 \mathrm{~min}$. PCR products were purified using the QIAquick PCR purification kit (QIAGEN).

Microsatellite markers D2S443, D16S752, D21S1436 (multiplex 2) and D1S104, D3S1284 (multiplex 3) were amplified in two multiplex PCR reactions under following conditions: $200 \mathrm{ng}$ DNA, $1 \times$ PCR buffer, $0.08 \mathrm{mM}$ dNTPs each, $2 \mathrm{mM} \mathrm{MgCl}$, $1 \mathrm{U}$ Taq, $0.8 \mu \mathrm{M}$ primer each, ad $50 \mu \mathrm{L} \mathrm{H} 2 \mathrm{O} ; 94^{\circ} \mathrm{C}$ for $2 \mathrm{~min}\left(94^{\circ} \mathrm{C}\right.$ for $40 \mathrm{~s}, 53^{\circ} \mathrm{C}$ (multiplex 2), and $61^{\circ} \mathrm{C}$ (multiplex 3) for $40 \mathrm{~s}$, respectively, $72^{\circ} \mathrm{C}$ for $1.30 \mathrm{~min}$ ), 40 cycles, $72^{\circ} \mathrm{C}$ for $2 \mathrm{~min}$. PCR products derived from the same patients sample were combined and purified using the PCR-purification kit (Qiagen). LOH analysis was performed on an automated capillary sequencer CEQ 8000 (Beckman Coulter) and evaluated with the CEQ 8000 Fragment analysis software (Beckman Coulter).

\section{LOHscoring}

The tumor was considered to be positive for $\mathrm{LOH}$ if the allele peak ratio was $\leq 0.7$, in analogy with allelic signal reduction of at least 30\% [10]. Homozygous peaks were classified as not informative and were not evaluated in LOH statistics.

\section{Literature review}

A Medline search was conducted for the term 'VIPoma'to December 2011. A total of 489 publications were retrieved. All English written publications reporting on oncogenesis were included. Articles dealing with clinical 
Table 1 Comparison of gene up- and downregulation of the primary pancreatic tumor against its corresponding healthy pancreatic tissue ( $>\log 2)$

\begin{tabular}{|c|c|c|c|}
\hline Geneproduct upregulated & Log2ratio & Geneproduct downregulated & Log2ratio \\
\hline Homo sapiens SMAD family member 5 (SMAD5) & 2.60 & Homo sapiens catenin (CTNNAL1) & -2.01 \\
\hline Homo sapiens neural cell adhesion molecule 2 (NCAM2) & 2.56 & Homo sapiens adhesion regulating molecule 1 (ADRM1) & -2.04 \\
\hline Homo sapiens cadherin-like 26 (CDH26) & 2.46 & Homo sapiens histonedeacetylase 2 (HDAC2) & -2.29 \\
\hline Homo sapiens S100 calcium binding protein A9 (S100A9) & 2.32 & Homo sapiens cyclin L2 (CCNL2) & -2.34 \\
\hline $\begin{array}{l}\text { Homo sapiens mediator of DNA damage checkpoint } 1 \\
\text { (MDC1) }\end{array}$ & 2.25 & Homo sapiens MSH2 (MSH2) & -2.63 \\
\hline \multirow[t]{3}{*}{ Homo sapiens adhesion molecule, (AMICA1) } & 2.24 & Homo sapiens SMAD family member 6 (SMAD6) & -2.71 \\
\hline & & $\begin{array}{l}\text { Homo sapiens guaninenucleotide binding protein ( } G \\
\text { protein) }\end{array}$ & -2.72 \\
\hline & & Homo sapiens cyclin-dependent kinase 5, (CDK5R2) & -3.02 \\
\hline
\end{tabular}

findings, diagnostics, therapy options, and clinical outcomes were excluded.

\section{Results}

\section{Microarray analysis}

Gene expression analysis was performed using a customdesigned oligo microarray. We found a number of genes that were up- or downregulated comparing the primary tumor, the metastases, the corresponding healthy tissue of the liver, and the pancreas.

Concerning the expression ratio we found 36 genes to be differentially expressed (>log2). Eighteen genes upregulated and 18 genes were downregulated. Comparing the primary pancreatic tumor against its corresponding healthy tissue six genes were upregulated and eight genes were downregulated $(>\log 2)$ (See Table 1). Five genes were upregulated and five genes were downregulated comparing the primary pancreatic tumor with the hepatic metastases $(>\log 2)$ (see Table 2 ). Regarding the expression between the hepatic metastases and its corresponding healthy liver tissue, seven genes were upregulated and five genes were downregulated (>log2) (see Table 3).

Regarding the gene expression of MSH2 and CXCR4 we were able to detect a downregulation ( -2.80 -fold) of
MSH2 in hepatic metastases and (-2.63-fold) of MSH2 in the primary pancreatic tumor compared to both corresponding healthy tissue. Comparing the hepatic metastases against the primary pancreatic tumor an upregulation (10.41-fold) was detected.

\section{$\mathrm{LOH}$ results}

Ten microsatellite samples were used for MSI and LOH detection (see Table 4).

All experiments were repeated at least twice. $\mathrm{LOH}$ events were detected in several patient samples (see Figure 2). Altogether, allele peak ratios for $\mathrm{LOH}$ calculation varied between 0.60 and 0.12 .

Sixty-three percent of markers analyzed showed LOH. Nine percent of markers were not informative for $\mathrm{LOH}$ calculation and $27 \%$ of markers showed microsatellite stability. LOH was detected in primary tumor DNA as well as in liver metastasis. Interestingly, two markers (D5S326 and D21S1436) revealed LOH in normal liver tissue. All tumor DNAs analyzed showed LOH for marker D2S123 which is located close to the MSH2.

\section{Discussion}

VIP-producing tumors arise from pancreatic islet cells and are mostly located in the pancreatic body or tail [4].

Table 2 Comparison of gene up- and downregulation of the primary pancreatic tumor against the hepatic metastases $(>\log 2)$

\begin{tabular}{|c|c|c|c|}
\hline Geneproduct upregulated & Log2ratio & Geneproduct downregulated & Log2ratio \\
\hline Homo sapiens cyclin-dependent kinase 7 (CDK7) & 4.52 & Homo sapiens acyl-CoA synthetase, (ACSM1) & -2.17 \\
\hline Homo sapiens cadherin $4(\mathrm{CDH} 4)$ & 3.72 & Homo sapiens cadherin 20, type $2(\mathrm{CDH} 20)$ & -2.27 \\
\hline Homo sapiens cyclin D2 (CCND2) & 3.06 & Homo sapiens HUS1 checkpoint (HUS1B) & -2.67 \\
\hline $\begin{array}{l}\text { Homo sapiens gapjunctionprotein, beta } 5 \text { (connexin 31.1) } \\
\text { (GJB5) }\end{array}$ & 2.73 & Homo sapiens chemokine (C-X-C motif) receptor 4 (CXCR4) & -3.37 \\
\hline Homo sapiens lipase, hormone-sensitive & 2.25 & $\begin{array}{l}\text { Homo sapiens caudal type homeobox ranscription factor } 2 \\
\text { (CDX2) }\end{array}$ & -3.39 \\
\hline
\end{tabular}


Table 3 Comparison of gene up- and downregulation of the hepatic metastases and its corresponding healthy liver tissue (>log2)

\begin{tabular}{|c|c|c|c|}
\hline Geneproduct upregulated & Log2ratio & Geneproduct downregulated & Log2ratio \\
\hline Homo sapiens neuronal cell adhesion molecule (NRCAM) & 2.76 & $\begin{array}{l}\text { Homo sapiens guanine nucleotide binding protein-like } 2 \\
\text { (GNL2) }\end{array}$ & -2.23 \\
\hline Homo sapiens GNAS complex locus (GNAS) & 2.58 & $\begin{array}{l}\text { Homo sapiens alanine-glyoxylate aminotransferase homolog } \\
\text { (TLH6) }\end{array}$ & -2.38 \\
\hline $\begin{array}{l}\text { Homo sapiens cell division cycle and apoptosis regulator } 1 \\
\text { (CCAR1) }\end{array}$ & 2.51 & Homo sapiens MSH2 (MSH2) & -2.80 \\
\hline Homo sapiens cyclin-dependent kinase inhibitor (CDKN1C) & 2.48 & Homo sapiens gap junction protein, beta 1 (GJB1) & -2.87 \\
\hline $\begin{array}{l}\text { Homo sapiens cytochrome c oxidase subunit Vlla polypeptide } \\
2 \text { (liver) }\end{array}$ & 2.29 & Homo sapiens caspase 1 (CASP1) & -3.21 \\
\hline Homo sapiens mucin and cadherin-like (MUCDHL) & 2.09 & & \\
\hline Homo sapiens cyclin D1 (CCND1) & 2.04 & & \\
\hline
\end{tabular}

Malignancy is solely defined by existing distant metastasis [11]. The clinical symptoms accompanying the tumor are watery diarrhea, hypokalemia, and metabolic acidosis. At the time of presentation, over $70 \%$ of patients had hepatic metastases [12]. Hence, understanding the molecular mechanisms of tumor progression is of paramount importance. Our results revealed defects in the mismatch repair system especially in MSH2. MSH2 showed significantly lower expression in the primary pancreatic tumor and its liver metastases than in healthy pancreatic tissue. Further an overexpression of CXCR4 in the hepatic metastasis compared with the primary was detected.

Reviewing the literature,eight cohorts including 161 patients and 133 case reports exist on VIPoma. Only six publications deal with the molecular mechanisms of oncogenesis and metastasis development in VIPoma, reporting no more than two cases in each publication [13-18]. The remaining publication reports on the clinical presentation, diagnostics, and therapeutic options. Amongst others, mutations in the tumor suppression genes DPC4 [15], AIM1 ('absent in melanoma1') and PTPRK (receptor type protein-tyrosine phophastase kappa) [14] are shown in metastatic VIPomas while mutations of the proto oncogene BRAF known to play an important role in thyroid cancer and melanoma were not found $[15,18]$. A series of 35 neuroendocrine tumors of the pancreas showed that defects in DNA mismatch repair are rather rare with the limitation, that no VIPoma case was included [19].

The DNA mismatch repair system (MMR) corrects base mismatches after DNA replication, avoids recombination between non-identical DNA sequences, and induces apoptotic and checkpoint responses after DNA damage

Table 4 Microsatellite markers used for MSI and LOH detection in pancreatic tumor tissue, liver metastasis tissue, and normal liver tissue

\begin{tabular}{|c|c|c|c|c|c|c|c|c|}
\hline \multirow[b]{2}{*}{ Marker } & \multirow[b]{2}{*}{ Localization } & \multirow[t]{2}{*}{ Tissue } & \multicolumn{2}{|c|}{ Pancreatic tumor } & \multicolumn{2}{|c|}{ Liver metastasis } & \multicolumn{2}{|c|}{ Normal liver } \\
\hline & & & & AP ratio & & AP ratio & & AP ratio \\
\hline D1S104 & $1 q 21-23$ & & $\mathrm{LOH}$ & 0.2 & $\mathrm{LOH}$ & 0.49 & MSS & $>0.7$ \\
\hline D2S443 & $2 p 13$ & & $\mathrm{LOH}$ & 0.19 & $\mathrm{LOH}$ & 0.42 & MSS & $>0.7$ \\
\hline BAT26 & $2 p 16$ & & MSS & $>0.7$ & MSS & $>0.7$ & MSS & $>0.7$ \\
\hline D2S123 & $2 p 16$ & & $\mathrm{LOH}$ & 0.21 & $\mathrm{LOH}$ & 0.45 & MSS & $>0.7$ \\
\hline D3S1284 & $3 p 12$ & & $\mathrm{LOH}$ & 0.19 & $\mathrm{LOH}$ & 0.47 & MSS & $>0.7$ \\
\hline BAT25 & $4 q 12$ & & MSS & $>0.7$ & MSS & $>0.7$ & MSS & $>0.7$ \\
\hline D5S326 & $5 q 22.2$ & & $\mathrm{LOH}$ & 0.2 & $\mathrm{LOH}$ & 0.31 & $\mathrm{LOH}$ & 0.32 \\
\hline D16S752 & $16 q 22$ & & $\mathrm{LOH}$ & 0.12 & $\mathrm{LOH}$ & 0.39 & MSS & $>0.7$ \\
\hline D17S250 & $17 q 11.2-12$ & & MSS & $>0.7$ & MSS & $>0.7$ & MSS & $>0.7$ \\
\hline D21S1436 & $21 q 21$ & & $\mathrm{LOH}$ & 0.6 & $\mathrm{LOH}$ & 0.4 & $\mathrm{LOH}$ & 0.59 \\
\hline
\end{tabular}

AP ratio, Allele peak ratio; LOH, Loss of heterozygosity; MSS, Microsatellite stable. 


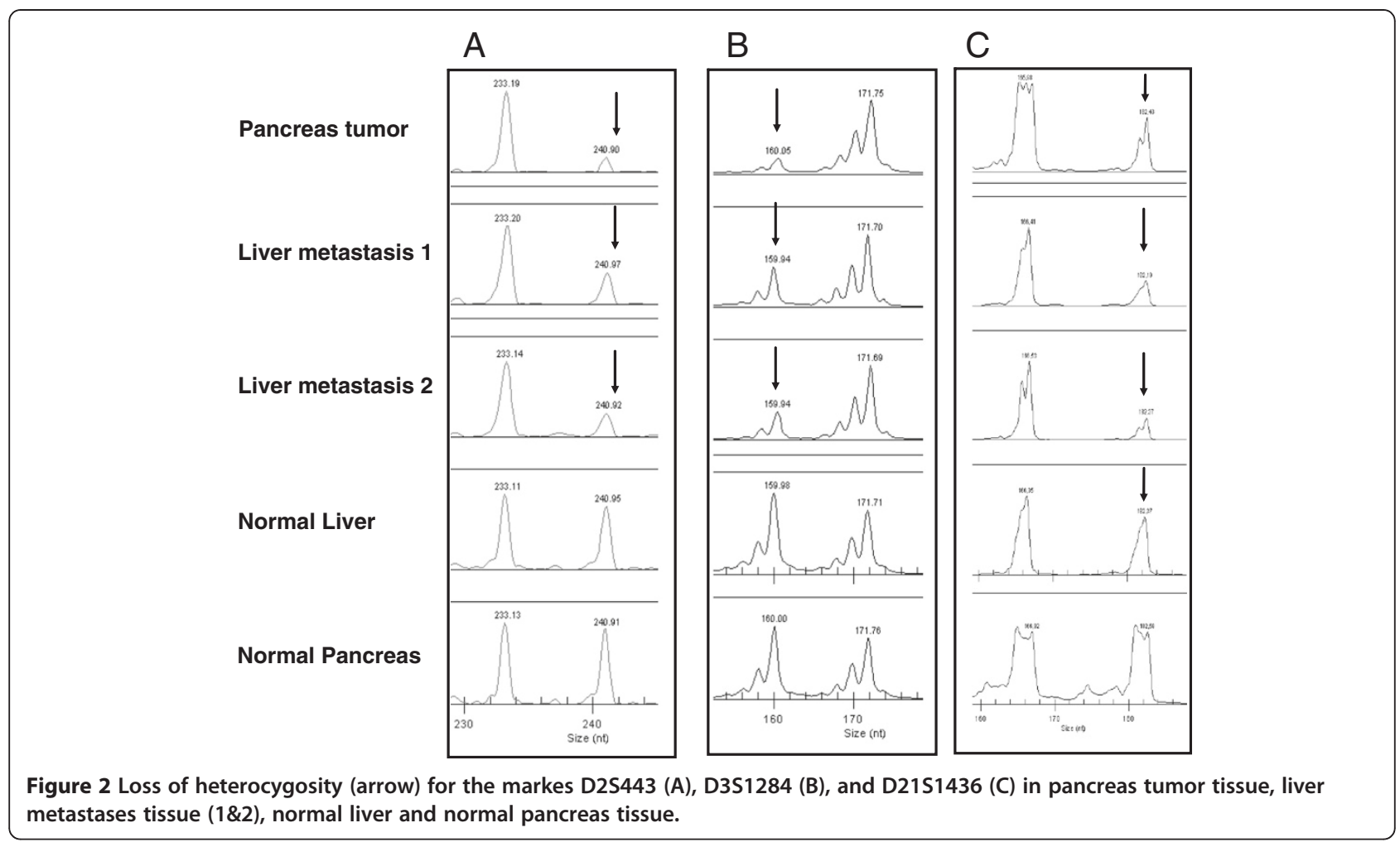

[20]. Besidespost-replication repair, MMR proteins are assumed to a great extent to be involved in carcinogenesis [21]. So far hundreds of different predisposing mutations are known, mainly affecting the MMR genes, MLH1, MSH2, and MSH6. Predisposed individuals exhibit a deficient copy of a MMR gene in each cell. Deficient MMR, characteristic in the colon can lead to proceeding accumulation of mutations and cancer, such as hereditary non-polyposis colon cancer (HNPCC), is known to be a syndrome of insufficient DNA mismatch repair genes [21]. Instability at short tandem repeat sequences, microsatellites, is a representative manifestation of MMR deficiency and beside HNPCC also occurs in other tumors [20]. In particular deficient MSH2 is associated with an increased risk of cancer [22].

Chemokines and their respective receptors have been identified as contributing metastatic factors in numerous cancers $[23,24]$. The common human chemokine system includes about 50 ligands and $20 \mathrm{G}$ protein-coupled receptors which control migration and activation of leukocytes and influences angiogenesis and tumor growth [25]. Recent discoveries assume that tumor cells themselves are able to secrete chemokines [25-27]. Therefore disseminated tumor cells that express members of the CXCR family and invade the circulation may be attracted and arrested by their corresponding ligand. Hence these cells gain the ability to infiltrate in distinct organs. CXCR4 is assumed to be involved in metastasis of non-small-cell lung, breast, pancreatic, prostate, gastric cancer, and peritoneal carcinomatosis [27-32]. Deschamps et al. found CXCR4 to be associated with the malignant metastatic progression of neuroendocrine tumors of the ileum correlated with a lower survival [33]. So far, mutation of MSH2 and CXCR4 and its involvement in tumor growth and metastasis development have not been reported in VIPoma.

\section{Conclusions}

Altogether, the altered expression of MSH2 and CXCR4 in a metastatic VIPoma might reflect higher tumor aggressivity with the potential development of distant metastases. Owing to the rarity of this disease, we believe these results will provide a valuable resource for future work on this serious condition with the potential of diagnostic applications.

\section{Competing interests}

This manuscript contains original material that has not been published or submitted to any other journal. The authors declare no competing interests.

\section{Authors' contributions}

SM and DZ designed the study, analysed the data and drafted the manuscript. SK carried out the LOH analysis. IK and FT carried out the molecular studies and helped to draft the manuscript. TB, KS and RK provided the pathologic specimen and helped to draft the manuscript. HN and AK helped to draft the manuscript. All authors read and approved the final manuscript. 


\section{Acknowledgments}

The authors gratefully acknowledge the effort and contributions to the present study, made by the technologists and staff, such as Melanie Hauth, Juergen Winter, Silvia Wagner, Christine Kienzle, and Caroline Zug for their help in sampling the tissues as well as Georg Otto and Robert Geisler, members of the Max Planck Institute in Tübingen, Germany, for their encouragement concerning microarray manufacture.

\section{Author details}

${ }^{1}$ Department of General, Visceral and Transplant Surgery, Tübingen, Germany. ${ }^{2}$ Department of Transfusion Medicine, Tübingen, Germany. ${ }^{3}$ Department of Molecular Pathology, Tübingen, Germany. ${ }^{4}$ Comprehensive Cancer Center, University of Tübingen, Tübingen, Germany. ${ }^{5}$ Department of General, Visceral and Transplant Surgery, Comprehensive Cancer Center, University of Tübingen, Hoppe-Seyler-Strasse 3, Tübingen D 72076, Germany.

Received: 6 August 2012 Accepted: 24 November 2012 Published: 11 December 2012

\section{References}

1. Verner $\mathrm{JV}$, Morrison $\mathrm{AB}$ : Islet cell tumor and a syndrome of refractory watery diarrhea and hypokalemia. Am J Med 1958, 25:374-380.

2. Friesen SR: Update on the diagnosis and treatment of rare neuroendocrine tumors. Surg Clin North Am 1987, 67:379-393.

3. Ectors N: Pancreatic endocrine tumors: diagnostic pitfalls. Hepatogastroenterology 1999, 46:679-690.

4. Ghaferi AA, Chojnacki KA, Long WD, Cameron JL, Yeo CJ: Pancreatic VIPomas: subject review and one institutional experience. J Gastrointest Surg 2008, 12:382-393.

5. $\quad$ Peng SY, Li JT, Liu YB, Fang HQ, Wu YL, Peng CH, Wang XB, Qian HR: Diagnosis and treatment of VIPoma in China: (case report and 31 cases review) diagnosis and treatment of VIPoma. Pancreas 2004, 28:93-97.

6. Grant CS: Surgical management of malignant islet cell tumors. World J Surg 1993, 17:498-503.

7. Zieker D, Zieker J, Dietzsch J, Burnet M, Northoff H, Fehrenbach E: CDNAmicroarray analysis as a research tool for expression profiling in human peripheral blood following exercise. Exerc Immunol Rev 2005, 11:1186-1196

8. Zieker D, Fehrenbach E, Dietzsch J, Fliegner J, Waidmann M, Nieselt K, Gebicke-Haerter P, Spanagel R, Simon P, Niess AM, Northoff H: cDNA microarray analysis reveals novel candidate genes expressed in human peripheral blood following exhaustive exercise. Physiol Genomics 2005, 23:287-294.

9. Kupka S, Haack B, Zdichavsky M, Mlinar T, Kienzle C, Bock T, Kandolf R, Kroeber SM, Konigsrainer A: Large proportion of low frequency microsatellite-instability and loss of heterozygosity in pheochromocytoma and endocrine tumors detected with an extended marker panel. J Cancer Res Clin Oncol 2008, 134:463-471.

10. Karnik P, Paris M, Williams BR, Casey G, Crowe J, Chen P: Two distinct tumor suppressor loci within chromosome $11 \mathrm{p} 15$ implicated in breast cancer progression and metastasis. Hum Mol Genet 1998, 7:895-903.

11. Capella C, Polak JM, Buffa R, Tapia FJ, Heitz P, Usellini L, Bloom SR, Solcia E: Morphologic patterns and diagnostic criteria of VIP-producing endocrine tumors. A histologic, histochemical, ultrastructural, and biochemical study of 32 cases. Cancer 1983, 52:1860-1874.

12. Jensen RT: Pancreatic endocrine tumors: recent advances. Ann Oncol 1999, Suppl: 4170-4176.

13. Barghorn A, Komminoth $P$, Bachmann D, Rutimann K, Saremaslani $P$ Muletta-Feurer S, Perren A, Roth J, Heitz PU, Speel EJ: Deletion at 3p25.3p23 is frequently encountered in endocrine pancreatic tumours and is associated with metastatic progression. J Pathol 2001, 194:451-458.

14. Barghorn A, Speel EJ, Farspour B, Saremaslani P, Schmid S, Perren A, Roth J, Heitz PU, Komminoth P: Putative tumor suppressor loci at $6 \mathrm{q} 22$ and 6q23-q24 are involved in the malignant progression of sporadic endocrine pancreatic tumors. Am J Pathol 2001, 158:1903-1911.

15. Bartsch D, Hahn SA, Danichevski KD, Ramaswamy A, Bastian D, Galehdari H, Barth P, Schmiegel W, Simon B, Rothmund M: Mutations of the DPC4/ Smad4 gene in neuroendocrine pancreatic tumors. Oncogene 1999, 18:2367-2371
16. Missiaglia E, Moore PS, Williamson J, Lemoine NR, Falconi M, Zamboni G, Scarpa A: Sex chromosome anomalies in pancreatic endocrine tumors. Int J Cancer 2002, 98:532-538.

17. Missiaglia E, Dalai I, Barbi S, Beghelli S, Falconi M, della Peruta M, Piemonti L, Capurso G, Di Florio A, delle Fave G, Pederzoli P, Croce CM, Scarpa A: Pancreatic endocrine tumors: expression profiling evidences a role for AKT-mTOR pathway. J Clin Oncol 2010, 28:245-255.

18. Tannapfel A, Vomschloss S, Karhoff D, Markwarth A, Hengge UR, Wittekind C, Arnold R, Horsch D: BRAF gene mutations are rare events in gastroenteropancreatic neuroendocrine tumors. Am J Clin Pathol 2005, 123:256-260.

19. Arnason T, Sapp HL, Rayson D, Barnes PJ, Drewniak M, Nassar BA, Huang WY: Loss of expression of DNA mismatch repair proteins is rare in pancreatic and small intestinal neuroendocrine tumors. Arch Pathol Lab Med 2011, 135:1539-1544.

20. O'Brien V, Brown R: Signalling cell cycle arrest and cell death through the MMR System. Carcinogenesis 2006, 27:682-692.

21. Peltomaki P: Deficient DNA, mismatch repair: a common etiologic factor for colon cancer. Hum Mol Genet 2001, 10:735-740.

22. Fishel R: Mismatch repair, molecular switches, and signal transduction. Genes Dev 1998, 12:2096-2101.

23. Kim J, Takeuchi H, Lam ST, Turner RR, Wang HJ, Kuo C, Foshaq L, Bilchik AJ, Hoon DS: Chemokine receptor CXCR4 expression in colorectal cancer patients increases the risk for recurrence and for poor survival. $J$ Clin Oncol 2005, 23:2744-2753.

24. Kim J, Mori T, Chen SL, Amersi FF, Martinez SR, Kuo C, Turner RR, Ye X, Bilchik AJ, Morton DL, Hoon DS: Chemokine receptor CXCR4 expression in patients with melanoma and colorectal cancer liver metastases and the association with disease outcome. Ann Surg 2006, 244:113-120.

25. Gerard C, Rollins BJ: Chemokines and disease. Nat Immunol 2001, 2:108-115

26. Bottazzi B, Polentarutti N, Acero R, Balsari A, Boraschi D, Ghezzi P, Salmona M, Mantovani A: Regulation of the macrophage content of neoplasms by chemoattractants. Science 1983, 220:210-212.

27. Muller A, Homey B, Soto H, Ge N, Catron D, Buchanan ME, McClanahan T, Murphy E, Yuan W, Wagner SN, Barrera JL, Mohar A, Verastequi E, Zlotnik A: Involvement of chemokine receptors in breast cancer metastasis. Nature 2001, 410:50-56.

28. Oonakahara K, Matsuyama W, Higashimoto I, Kawabata M, Arimura K, Osame M: Stromal-derived factor-1alpha/CXCL12-CXCR 4 axis is involved in the dissemination of NSCLC cells into pleural space. Am J Respir Cell Mol Biol 2004, 30:671-677.

29. Saur D, Seidler B, Schneider G, Algul H, Beck R, Senekowitsch-Schmidtke R, Schwaiger M, Schmid RM: CXCR4 expression increases liver and lung metastasis in a mouse model of pancreatic cancer. Gastroenterology 2005, 129:1237-1250.

30. Taichman RS, Cooper C, Keller ET, Pienta KJ, Taichman NS, McCauley LK: Use of the stromal cell-derived factor-1/CXCR4 pathway in prostate cancer metastasis to bone. Cancer Res 2002, 62:1832-1837.

31. Wang J, Wang J, Dai J, Jung Y, Wei CL, Wang Y, Havens AM, Hogg PJ, Keller ET, Pienta KJ, Nor JE, Wang CY, Taichman RS: A glycolytic mechanism regulating an angiogenic switch in prostate cancer. Cancer Res 2007 67:149-159.

32. Yasumoto K, Koizumi K, Kawashima A, Saitoh Y, Arita Y, Shinohara K, Minami T, Nakayama T, Sakurai H, Takahashi Y, Yoshie O, Saiki I: Role of the CXCL12/CXCR4 axis in peritoneal carcinomatosis of gastric cancer. Cancer Res 2006, 66:2181-2187.

33. Deschamps L, Bacha D, Rebours V, Mebarki M, Bretagnol F, Panis Y, Bedossa $P$, Ruszniewski $P$, Coulevard A: The expression of the hypoxia markers CA9 and CXCR4 is correlated with survival in patients with neuroendocrine tumours of the ileum. Neuroendocrinology 2012, 95:214-222.

doi:10.1186/1477-7819-10-264

Cite this article as: Müller et al:: MSH2 and CXCR4 involvement in malignant VIPoma. World Journal of Surgical Oncology 2012 10:264. 